\section{COLLOIDAL PREPARATIONS.}

\section{THE EXAMINATION OF COLLOIDAL SOLUTIONS. BY}

Sir WILLIAM J. POPE, K.B.E., F.R.S., D.Sc., LL.D., PROFESSOR OF CHEMISTRY, ONIVERSITY OF CAMBRIDGE.

A recent paper by Professor A. J. Clark (British Medical JounNaL, 1923, i, p. 273) contains a discussion of the customary methods for distinguishing colloidal solutions from those of crystalloids and details the results of the examination of a number of colloidal preparations found in commerce. It is stated that the work was carried out at the expense of the British Medical Association, and it may therefore be presumed to carry with it the authority and approbation of this important body ; this latter circumstance makes it particularly unfortunate that many, if not most, of the experimental re. sults recorded in the paper are erroneous and nisleading, and that, in consequence, the conclusions drawn are unjustified.

The refutation of an error is always a more lengthy process than is its original statement; without discussing detail by detail the sequence of mistakes made in the paper under discussion it will suffice, and the interests of brevity will be served, if Professor Clark's conclusions concerning bat one from among the many preparations with which he has dealt are shown to be unfounded.

The solution known as " colloidal ferrum Crookes" contains 0.05 per cent. of iron as a colloidal ferric compound, with about 0.5 per cent. of gelatin and about 3.5 per cent. of glucose, as may be ascertained by any competent analyst; it passes through filter paper without leaving a precipitate, and is faintly alkaline in reaction owing to the presence of a small proportion of sodium hydroxide. Presumably everyone is aware that ferric salts are precipitated by sodium hydroxide unless retained in colloidal solution by some protective sub. stance. The fact that sugars retain ferric iron in colloidal solution was recorded by Thomas Graham in his famous first paper on col!oids (Philosophical Transactions of the Royal Society, 1861, 151, 183), and has been the subject of much later experimental study. The simple and direct proof that such solutions contain the iron in the form of colloidally sus. pended particles, which can be seen in the ultramicroscope, is so complete that the colloidal character of these prepara. tions has never before been impugned.

But Professor Clark disregards the effect of the gelatin and the glucose and does not note the alkalinity of the solution, the factors which directly prove the colloidal condition of the iron in the preparation. He observes that the ferric compound passes through a collodion filter and thence concludes that the iron cannot be in a colloidal condition, oblivious of the fact that colloidal filters are in common use for separating fine and coarse colloidal suspensions, the finer readily traversing the filter.

Professor Clark remarks that extravagant statements con. cerning colloidal preparations have been often recorded, and that much of the "scientific" literature on the subject is uncritical; this is regrettably true so far as the medical literature is concerned, and makes it the more desirable that the British Medical Association and Professor Clark should discountenance the methods of the past and confine them. selves to the publication of properly ascertained facts with their logical conclusions. The dangers of not doing so have been eloquently depicted by Dr. H. H. Dale (Journ. Soc. Chem. Ind., 1920, 39, 211 R).

\section{OBSERVATIONS ON THE ABOVE ARTICLE.} BY

A. J. CLARK, M.D., F.R.C.P., PROFESSOR OF PHARMACOLOGY, UNIVERSITY COLLEGE, LONDON.

I have read the above article by Sir William Pope with surprise. He states of my paper "that many, if not most, of the experimental results recorded in the paper are erroneous and misleading." He does not, howerer, prodnce any evidence to show that a single experimental fact stated in my paper is incerrect. It is, of course, wcontwaxy. to every tradition of gcientific controversy to and to broeping charge the this without establishing it to the hilt. This is, however, a minor question.

Sir William Pope concentrates his attention on my findings as regards collosol ferrum, and says :

"The solution known as 'colloidal ferrum Crookes' contains 0.05 per cent. of iron as a colloidal ferric compound, with about 0.5 per cent. of gelatin and about 3.5 per cent. of glucose, as may be ascertained by any competent analyst; it passes through filter paper without leaving a precipitate, and is faintly alkaline in reaction owing to the presence of a small proportion of sodium hydroxide. . . But Professor Clark disregards the effect of the gelatin and the glucose and does not note the alkalinity of the solution, the factors which directly prove the colloidal condition of the iron in the preparation." (The italics are mine.)

Messrs. Crookes, as far as I am aware, have no preparation called "colloidal ferrum Crookes." The substance I investigated was "collosol ferrum Crookes," and I presume that Sir William Pope is referring to this, otherwise his remarks are pointless.

The two statements italicized in the above quotation relate to matters of elementary chemistry. I cannot confirm either of them.

During the past year I have tested six separate bottles of collosol ferrum Crookes bought over a period from January 1922, until April, 1923; some were bought from retail and some from wholesale chemists. In every instance the solution was acid. To-day (April 19th) I opened two new bottles of collosol ferrum; one bottle had been recently obtained from a wholesale chemist and the other came to-day from Messrs. Crookes's establishment in Chenies Street; the contents of both bottles were acid: the acidity corresponded approximately to $N / 200$ and $N / 500$ acid respectively. Having made these observations and measured the degree of acidity 1 cannot quarrel with Sir William Pope's statement that I do "not note the alkalinity of the solution."

Collosol ferrum gives all the reactions characteristic of a dilute solution of a ferrous salt-namely, a deep blue colour with potassium ferricyanide which develops immediately, a paler blue colour with potassium ferrocyanide which develops slowly, and no colour with ammonium sulphocyanide. These reactions are totally different from those given either by an ordinary solution of a ferric salt or by a solution of colloidal iron.

As regards precipitate, five out of the six specimens which I have examined left a heavy precipitate when filtered through a filter paper. One of the two bottles examined to-day yields 0.08 per cent. of precipitate on filtration; the other bottle, obtained fresh to-day from Messrs. Crookes, gives no precipitate.

As regards colloidal condition, I showed in my paper that the iron in collosol ferrum, when tested by dialysis, ultra filtration, or diffusion, behaved exactly as if in true solution. Sir William Pope argues that the iron in "colloidal ferrum" must be colloidal because it is in the ferric state and the solution is alkaline. The iron, however, is in the ferrous state and the solution is acid.

So far as I understand Six William Pope, the only other evidence he adduces is that the solution shows colloidal particles on ultramicroscopic examination and contains gelatin and sugar. If $\mathrm{my}$ interpretation of Sir William Pope's statement be correct, I will leave it to chemists with experience of colloidal chemistry to say what thoy think of the argument that iron in a solution must be colloidal if the solution contains-particles visible under the ultramicroscope, and also contains gelatin and sugar.

Sir William Pope, however, really bases his argument on the alkaline reaction of the fluid. When a person in his position bases an important argument on an elementary fact like this, and one finds that the statement is wholly incorrect as regards six separate samples of the substance under investigation, discussion becomes very difficult.

In the above circumstances it seems unnecessary to notice Sir William Pope's unkind remarks about my. methods of research. - In my paper I dealt with collosol ferruın - Crookes as sold to the medical profession. Sir William Pope has publicly ridicaled me for failing to notice that it is alkaline. I say that it is acid, and that anyone who is in doubt can determine this point for himself wilh a piece o $\dot{t}$ litums paper. 